\title{
EXPLORATORY TRAFFIC NOISE MEASUREMENTS AT FIVE MAIN STREETS OF THESSALONIKI, GREECE
}

\section{E. Georgiadou', K. Kourtidis ${ }^{2, *}$, I. Ziomas 3}

\author{
${ }^{1}$ Laboratory of Atmospheric Physics, \\ Department of Physics, \\ Aristotle University of Thessaloni, Greece \\ ${ }^{2}$ Lab. of Atmospheric Pollution and \\ Control Engineering of Atmospheric Pollutants, \\ Department of Environmental Engineering, \\ School of Engineering, \\ Demokritus University of Thrace, \\ Xanthi, Greece \\ ${ }^{3}$ Scool of Chemical Engineering, \\ Department of Process Analysis and Plant Design \\ National Technical University of Athens \\ Athens, Greece
}

*to whom all correspondence should be addressed:

Fax: $+(30)$ 25410-79379

\begin{abstract}
Although noise is a very common nuisance in Greek cities, information on actual noise levels in streets is sparse. Here, noise measurements at five main streets of Thessaloniki, Greece for about five weeks are presented. Ten minute, one hour and daily average noise levels were calculated. Traffic noise levels were significant in every examined street during the study. In all streets, the diurnal variation of noise levels and traffic volume exhibited significant correlation, with $\mathrm{r}^{2}$ up to 0.92 . Noise measurements at two heights in one street showed a difference of around $14 \mathrm{db}$ between the $1^{\text {st }}$ and the $8^{\text {th }}$ floor. The noise levels difference between working days and weekends was around 1-2 dB during daytime, but it changed sign during the late night hours. The latter can be attributed to night-life recreational traffic during weekends. Noise levels from 7:00 to 24:00 were around 63-66 dB in the $1^{\text {st }}$ and $2^{\text {nd }}$ floors of all four streets where measurements were made at these floors. In these cases, the quietest period was between 4:00 and 6:00, but even then, in three out of four cases noise levels were above $60 \mathrm{~dB}$. Although no exceedances have been observed, the mean daily values, i.e. $\mathrm{L}_{\mathrm{eq}}(08: 00-20: 00)$, are close to the national limit of $67 \mathrm{~dB}(\mathrm{~A})$. This exploratory measurements show that Thessaloniki has a traffic noise problem, which is likely to become more acute, if the $6 \%$ annual increase in traffic volume experienced during the previous decade is to continue.
\end{abstract}

KEYWORDS: traffic noise. 


\section{INTRODUCTION}

High noise levels constitute a serious, although at times neglected, environmental problem because of its effects on the well-being and health of people. The possibility that noise has negative effects on human health has been a strong impetus for research and a major argument for noise control. People's well-being is diminished by noise, so in this sense of the term there is no doubt that noise affects health. Very loud sounds are highly injurious to man as well as animals. The negative effects on the auditory system of prolonged exposure to high levels of noise in industrial settings are well established. Long-term exposure to high noise levels can also result in permanent hearing loss, this effect being associated mainly with occupational noise (Nelson, 1987).

In contrast, the causal link between community noise (including transportation noise) and both auditory and non-auditory health effects remains less certain. This is because lower-level noise effects are more difficult to prove, but sufficient evidence exists for a number of effects. Although evidence is inconclusive on others, such as cardiovascular disease (e.g. Babisch et al., 1990), this does not mean that these effects do not exist. Apart from the definite annoyance, sufficient conclusive evidence for noise effects on school children performance (IEH, 1997), sleep quality (IEH, 1997; Morrell et al., 1997; NHC, 1997), heart rate (NHC, 1997) and stress-related ischaemic heart disease (NHC, 1997). These reactions are not confined to high noise levels and sudden noise events, but are also apparent for noise levels commonly experienced in environments such as busy streets.

There can be no doubt that in Greek cities road transport constitutes the greatest source of noise in the majority of an urban area. This noise source is of great importance, as it might constitute the main term of exposure to noise to the majority of the population. While controlling road traffic noise by treatments at source (such as to reduce engine noise, exhaust pipe noise etc.) is to be encouraged as the principal method of control, measures which attempt to limit the spread of noise, once generated, are also of considerable value. The techniques include road design, the management of traffic flow and the use of screens and barriers, although the latter is in most cases not applicable to city streets. Traffic noise measurements and estimation can contribute significantly to the development of efficient methods of control.

In the present study, traffic noise measurements have been made in order to obtain an estimate of traffic noise in some streets of Thessaloniki with relatively high traffic loads. 10-min, 1-hr and daily mean noise levels were calculated, while a correlation between traffic noise and traffic volume in each examined street has been calculated by the measurements. Differences in noise levels between weekends and working days as well as differences at two different floors in the same building were also examined.

Except for the very low frequencies, the human brain does not respond to the instantaneous pressure. Rather, it behaves as an integrator perceiving a signal, which depends upon what has happened just previously (Nelson, 1987). An equivalent signal can be realized mathematically by squaring and integrating the instantaneous pressure fluctuation $\mathrm{p}(\tau)$, dividing by the integration time and then taking the square root. The result is known as the root mean square (rms) value and is defined as follows:

$\overline{\mathrm{p}}=\left[\frac{1}{\mathrm{~T}} \int_{t-T}^{t} \mathrm{p}(\tau)^{2} \mathrm{~d} \tau\right]^{\frac{1}{2}}$

Equation (1) represents a "linear" averaging process in which the squared signal has been averaged over the time $\mathrm{T}$ immediately prior to the actual time t. Equal weighting is given to all parts of the signal that fall within the period $\mathrm{T}$ and this period can be chosen at will to suit the occasion. If the signal is averaged over a long time period, e.g. 1, 8 or 24 hours, what is referred to as the "equivalent" level over the defined time period is obtained.

Human hearing calculates an average in which the instantaneous perceived level depends more upon the present and less upon the past pressure fluctuations. "Exponential" averaging is a suitable mathematical representation of this process. In this case the rms pressure is given by:

$\bar{p}=\left[\frac{1}{R C} \int_{-\infty}^{t} p^{2}(\tau) \cdot e^{\frac{(\tau-t)}{R C}} \cdot d \tau\right]^{\frac{1}{2}}$ 
where $\mathrm{RC}$ is the time constant of the averaging circuit (Nelson, 1987). In practice the exponential weighting attaches greatest significance to the most recent fluctuations.

Sound level is specified in decibels instead of Pascals. Decibels constitute a logarithmic scale well suited to represent human hearing, which is rather logarithmic than linear in its behaviour. Thus, a scale based on the tenfold logarithm of the ratio of the measured quantity divided by a reference quantity can be considered reliable. The reference acoustic power is $10^{-12} \mathrm{~W}$, thus the acoustic power level is defined as:

$\mathrm{L}_{\mathrm{w}}=10 \cdot \log _{10} \frac{\mathrm{W}}{10^{-12}}$

where $\mathrm{W}$ is the acoustic power of the noise source in Watts (Nelson, 1987).

Since the acoustic power is proportional to the square of the pressure, the sound pressure level can be defined as:

$$
\mathrm{L}_{\mathrm{p}}=10 \cdot \log _{10} \frac{\overline{\mathrm{p}}^{2}}{\overline{\mathrm{p}}_{\mathrm{o}}{ }^{2}}=20 \cdot \log _{10} \frac{\overline{\mathrm{p}}}{\overline{\mathrm{p}}_{\mathrm{o}}}
$$

where $p$ is the measured sound pressure in $\mathrm{dB}$ and $\mathrm{p}_{\mathrm{o}}$ is the reference sound pressure.

Noise can be measured as well as analysed with the aid of various methods, which aim to either describe it precisely or relate it to human reactions. Its estimation can be considered as a threestep process.

The first step is to isolate the noise from other influencing factors and devise a measurement of level, which emulates the ear's variation of sensitivity with frequency. At this stage time is not included, so the level is a function of time. The "A", "B", "C" and "D" weighted levels, each one of them is characterised by a different frequency weighting, fall into this category.

The second step is to combine level with time in some way to give a scale. This may be the level exceeded for a given proportion of the time as in the statistical level or it may be an integration of level with respect to duration as in equivalent level. The rating or index constitutes the third step in which the time period is clearly specified. The more frequently used sound level is the Aweighted $\left(\mathrm{L}_{\mathrm{A}}\right)$, which is the sound level measured by a sound level meter using an A filter. This fil- ter weights differently every frequency and approaches satisfactory the human hearing. In fact, the A-weighting is now used for all levels of noise and a noise measurement is given in units of $\mathrm{dB}(\mathrm{A})$. Since the A-weighting was introduced, there have been several surveys correlating subjective reaction with objective measurements (Nelson, 1987), but no weighting was proved to be significantly better than the A-weighting, which is why it has now been almost universally adopted for the measurement of transport noise.

As far as a non-constant noise source is concerned, the equivalent continuous sound level $\mathrm{L}_{\mathrm{eq}}$ is applied. $\mathrm{L}_{\mathrm{eq}}$ is defined as the constant level containing the same quantity of sound energy over a defined period as the actual time varying sound level. The level is invariably A-weighted prior to the averaging process:

$$
\begin{aligned}
\mathrm{L}_{\text {Aeq }} & =10 \cdot \log _{10}\left[\frac{1}{\mathrm{~T}} \int_{0}^{\mathrm{T}} \frac{\mathrm{p}(\mathrm{t})^{2}}{\mathrm{p}_{\mathrm{o}}{ }^{2}} \mathrm{dt}\right]= \\
& =10 \cdot \log _{10}\left[\frac{1}{\mathrm{~T}} \int_{0}^{\mathrm{T}} 10^{0.1 \cdot \mathrm{L}_{\mathrm{i}}} \mathrm{dt}\right]
\end{aligned}
$$

where $\mathrm{L}_{i}$ is calculated according to the equation (4). $\mathrm{T}$ is the time period over which $\mathrm{L}_{\mathrm{Aeq}}$ is defined and has to be relatively long e.g. 1, 8, 12, or 24 hours. If the method used takes discrete measurements then the following formula is used:

$\mathrm{L}_{\text {Aeq }}=10 \cdot \log _{10}\left(\frac{1}{\mathrm{~T}} \sum_{\mathrm{i}=1}^{\mathrm{n}} 10^{0.1 \mathrm{~L}_{\mathrm{i}}} \mathrm{t}_{\mathrm{i}}\right)$

where $\mathrm{n}$ is the number of measurements. $\mathrm{L}_{\mathrm{eq}}$ is often a measure of traffic noise as well as the statistical levels $\mathrm{L}_{10}, \mathrm{~L}_{50}$ and $\mathrm{L}_{90}$, which are the levels, exceeded for $10 \%, 50 \%$ and $90 \%$ of the time, respectively. $\mathrm{L}_{10}$ gives an indication of the upper end of the level range, although it can be substantially less than occasional peaks. $\mathrm{L}_{90}$ corresponds to the background noise level in the absence of nearby noise sources (O'Cinneide, 1997). For freely flowing traffic, there is an empirical relationship between $\mathrm{L}_{10}$ and $\mathrm{L}_{\mathrm{eq}}$ (Nelson, 1987):

$\mathrm{L}_{10}=\mathrm{L}_{\mathrm{eq}}+3 \mathrm{~dB}(\mathrm{~A})$ 
Table 1. Measurement location and duration

\begin{tabular}{|c|c|c|c|}
\hline Street & Floor & Height above street $(\mathbf{m})$ & Time period \\
\hline Vasilissis Olgas & $2^{\text {nd }}$ & 8 & $6 / 5 / 98-11 / 5 / 98$ \\
\hline Antheon & $8^{\text {th }}$ & 25 & $11 / 5 / 98-14 / 5 / 98$ \\
\hline Antheon & $1^{\text {st }}$ & 3.5 & $14 / 5 / 98-20 / 5 / 98$ \\
\hline Nea Egnatia & $1^{\text {st }}$ & 4 & $23 / 5 / 98-2 / 6 / 98$ \\
\hline Mitropoleos & $6^{\text {th }}$ & 20 & $6 / 6 / 98-9 / 6 / 98$ \\
\hline Egnatia & $1^{\text {st }}$ & 5 & $10 / 6 / 98-16 / 6 / 98$ \\
\hline
\end{tabular}

However, this equation is not valid for vehicle flows of less than about 100 vehicles per hour. For both the quantitative and the qualitative estimation of traffic noise, the index of transportation noise is defined by the indexes $\mathrm{L}_{\mathrm{eq}}$ or $\mathrm{L}_{10}\left(18\right.$ hours). The $\mathrm{L}_{\mathrm{eq}}$ is defined for the time period 08:00 - 20:00. Thus the index is $\mathrm{L}_{\mathrm{eq}}(8-20)$. The index $\mathrm{L}_{10}(18$ hours $)$ is the numerical mean of 18 discrete hourly values of $\mathrm{L}_{10}$ (from 06:00 am to 24:00 pm) (National Law 17252/92, Official Journal of the Hellenic Parliament, 395 $\mathrm{B} / 19-6-92)$.

\section{EXPERIMENTAL}

A Reten Electronics RS103 sound level meter with a stable high-grade condenser electret microphone and an A-filter was used for the present study. Its accuracy conforms to IEC 65 Type 2, which represents sound level meters suitable for general field applications. The measuring range is $25 \mathrm{~dB}(\mathrm{~A})-130 \mathrm{~dB}(\mathrm{~A})$ or $40 \mathrm{~dB}-130 \mathrm{~dB}$ linear. The wide measurement range allows the instrument to be used for a diverse range of noise investigations where both high and low sound levels occur. Great care was taken to retain a distance between the instrument and the surrounding building walls or other obstacles that could intensify or reduce the received noise.

Measurements took place at five main streets of Thessaloniki and they were registered on a PC connected to the sound level meter's analog 0-1 V output. The stored 1-sec values were subsequently processed to calculate the desired averages. For each street and every examined day, $10 \mathrm{~min}$, and 1 hour means were calculated, as well as the index $\mathrm{L}_{\mathrm{eq}}(8-20)$ and the $\mathrm{L}_{10}$ (18 hours). When it was not possible to calculate the index $\mathrm{L}_{\mathrm{eq}}(8-20)$ directly, its 12 hour mean of the corresponding hourly measurements was used. In addition, the equation (7) was used to calculate $\mathrm{L}_{10}$ (18hours).

\section{RESULTS AND DISCUSSION}

Only limited measurements of traffic noise in Greece have been reported (Stathis, 1981). To the authors' knowledge, this is the first time that such measurements are reported outside "grey literature" for Thessaloniki, although, with around $1,000,000$ inhabitants, it is the second largest city in Greece and exhibits serious traffic problems.

In the present work, measurements were done at five main streets of Thessaloniki (Table 1), all with quite high traffic volume: Antheon Street, Egnatia Street, Nea Egnatia Street, Vasilissis Olgas Street and Mitropoleos Street. In the case of Antheon Str., the instrument was placed on the $1^{\text {st }}$ as well as on the $8^{\text {th }}$ floor of a building, while in the cases of Egnatia Str.and Nea Egnatia Str. it was placed on the $1^{\text {st }}$ floor, in Vasilissis Olgas Str. it was placed on the $2^{\text {nd }}$ floor and in Mitropoleos Str. it was placed on the $6^{\text {th }}$ floor.

In Antheon Str., $1^{\text {st }}$ floor, $\mathrm{L}_{\mathrm{eq}}(8-20)$ varied between $64 \mathrm{~dB}(\mathrm{~A})$ and $66 \mathrm{~dB}(\mathrm{~A})$ during the examined 7-day period, while $\mathrm{L}_{10}(18$ hours) varied between $67 \mathrm{~dB}(\mathrm{~A})$ and $69 \mathrm{~dB}(\mathrm{~A})$. These values can be considered quite high, considering that the legislative national limits of these indices are $67 \mathrm{~dB}(\mathrm{~A})$ and $70 \mathrm{~dB}(\mathrm{~A})$, respectively. On the other hand, on the $8^{\text {th }}$ floor of the same building in Antheon Str., $\mathrm{L}_{\text {eq }}$ (8-20) varied between 52 $\mathrm{dB}(\mathrm{A})$ and $53 \mathrm{~dB}(\mathrm{~A})$ and $\mathrm{L}_{10}(18$ hours) between $55 \mathrm{~dB}(\mathrm{~A})$ and $56 \mathrm{~dB}(\mathrm{~A})$ (Figure not shown). It is worth noticing that in Antheon Str., $8^{\text {th }}$ floor, on the $13^{\text {th }}$ of May, 1998, three successive $10-\mathrm{min}$ means exceeded the level of $\mathrm{L}_{10}$ around 08:0009:00 (Figure 1). This is of importance, because the $\mathrm{L}_{10}$ index represents the level exceeded by the $10 \%$ of the measurements as they were recorded from the instrument (1 measurement/sec in our case). Therefore, when $\mathrm{L}_{10}$ is exceeded by a 10 -min mean this means that most of the instan- 


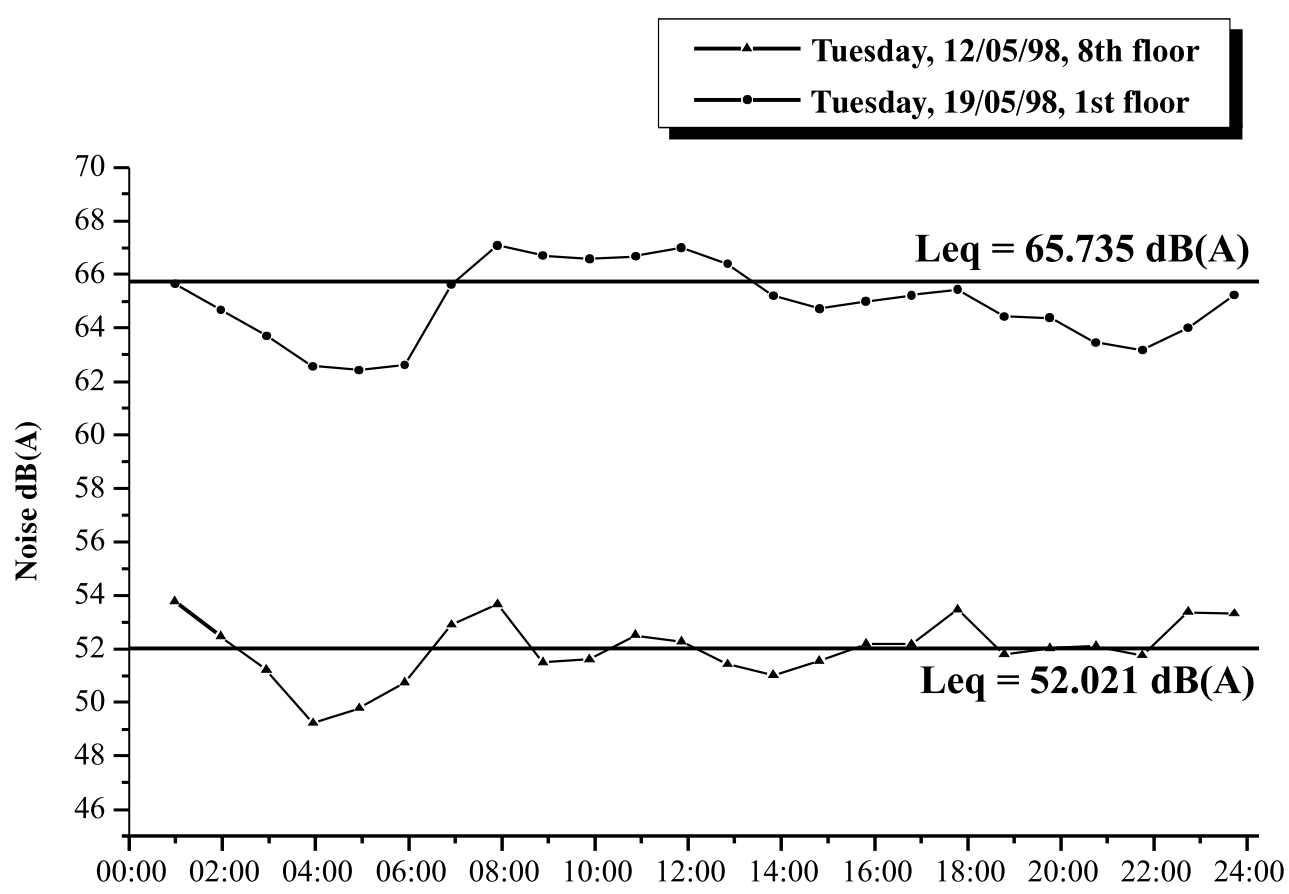

Time (hh:mm)

Figure 1. Diurnal variation of 1-hr and 10-min noise levels (left) and diurnal variation of noise levels during Tuesdays at two different levels at Antheon street (right)

taneous noise values during this time period exceeded this level. The event is even more significant in this case where there are three successive 10-min means exceeding the $\mathrm{L}_{10}$ level.

A comparative plot of 1-hour means taken on the $1^{\text {st }}$ and on the $8^{\text {th }}$ floor is also shown in Figure 1. A difference of $\sim 14 \mathrm{~dB}(\mathrm{~A})$ between the two $\mathrm{L}_{\mathrm{eq}}$ indices is observed. Hence, although the noise level on the $1^{\text {st }}$ floor is very close to the legislative limit of $67 \mathrm{~dB}(\mathrm{~A})$, on the $8^{\text {th }}$ floor it is lower than the lower limit of significant disturbance of $55 \mathrm{~dB}(\mathrm{~A})$.

Measurements at Nea Egnatia Str. took place, as mentioned above, on the first floor. $\mathrm{L}_{\mathrm{eq}}(8-20)$ varied between $\sim 62 \mathrm{~dB}(\mathrm{~A})$ and $\sim 64 \mathrm{~dB}(\mathrm{~A})$, while $\mathrm{L}_{10}(18$ hours) varied between $\sim 65 \mathrm{~dB}(\mathrm{~A})$ and $\sim 67$ $\mathrm{dB}(\mathrm{A}) . \mathrm{L}_{10}$ was exceeded considerably by four successive 10-min means taken around 09:00 am. The diurnal variation of 10-min noise levels for the $29^{\text {th }}$ of May, 1998 is shown in Figure 2. In the same Figure, a plot of weekend diurnal noise variation as compared with working days diurnal noise variation is also shown. It is observed that the two graphs follow the same daily pattern, although the variance is higher during the week- days. The noise levels difference between working days and weekends was around 1-2 dB during daytime, but it changed sign during the late night hours. The latter can be attributed to recreational traffic during weekends (traffic to and from bars, night clubs etc).

Measurements at Egnatia Str. took place again on the first floor. $\mathrm{L}_{\text {eq }}$ varied between $\sim 63 \mathrm{~dB}(\mathrm{~A})$ and $\sim 65 \mathrm{~dB}(\mathrm{~A})$, while $\mathrm{L}_{10}$ varies between $\sim 66 \mathrm{~dB}(\mathrm{~A})$ and $\sim 68 \mathrm{~dB}(\mathrm{~A})$ (Figure 2). A strong correlation between mean traffic volume and mean traffic noise at Egnatia Str. exists during the whole day, with a linear regression coefficient $\left(\mathrm{r}^{2}\right)$ of 0.92 (Figure 3). Although less pronounced, a correlation was observed at all the other streets as well (Figure not shown).

Measurements on the $6^{\text {th }}$ floor of a building at Mitropoleos Str. had $\mathrm{L}_{\text {eq }}$ varying between $\sim 55$ $\mathrm{dB}(\mathrm{A})$ and $\sim 59 \mathrm{~dB}(\mathrm{~A})$ and $\mathrm{L}_{10}$ between $\sim 58$ $\mathrm{dB}(\mathrm{A})$ and $\sim 62 \mathrm{~dB}(\mathrm{~A})$. It should be noted that the measurements were made on the $6^{\text {th }}$ floor and that they were frequently interrupted due to power failures. Hence, they might not be representatives of the actual noise levels. It is worth noticing that some exceedence of the $\mathrm{L}_{10}$ legisla- 


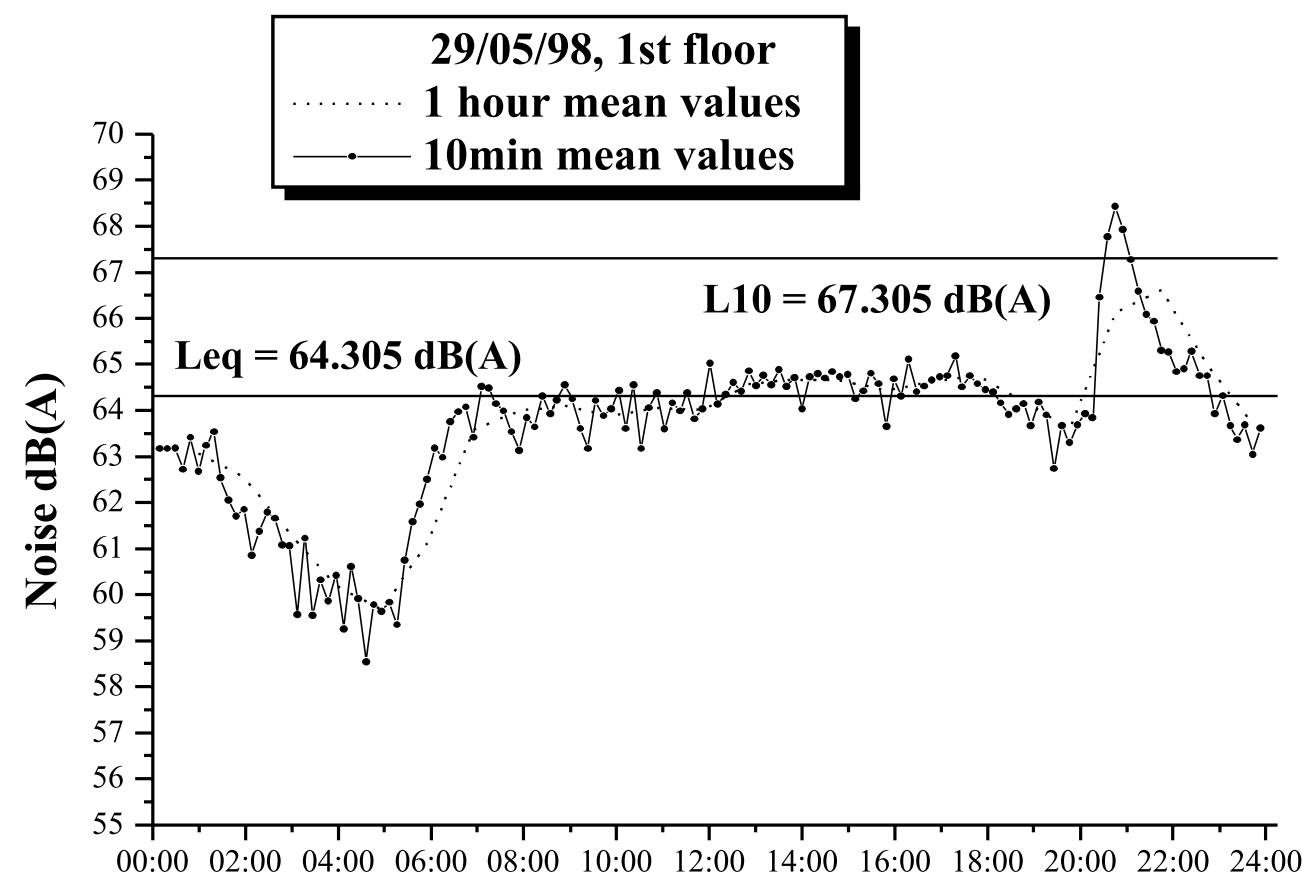

Time (hh:mm)

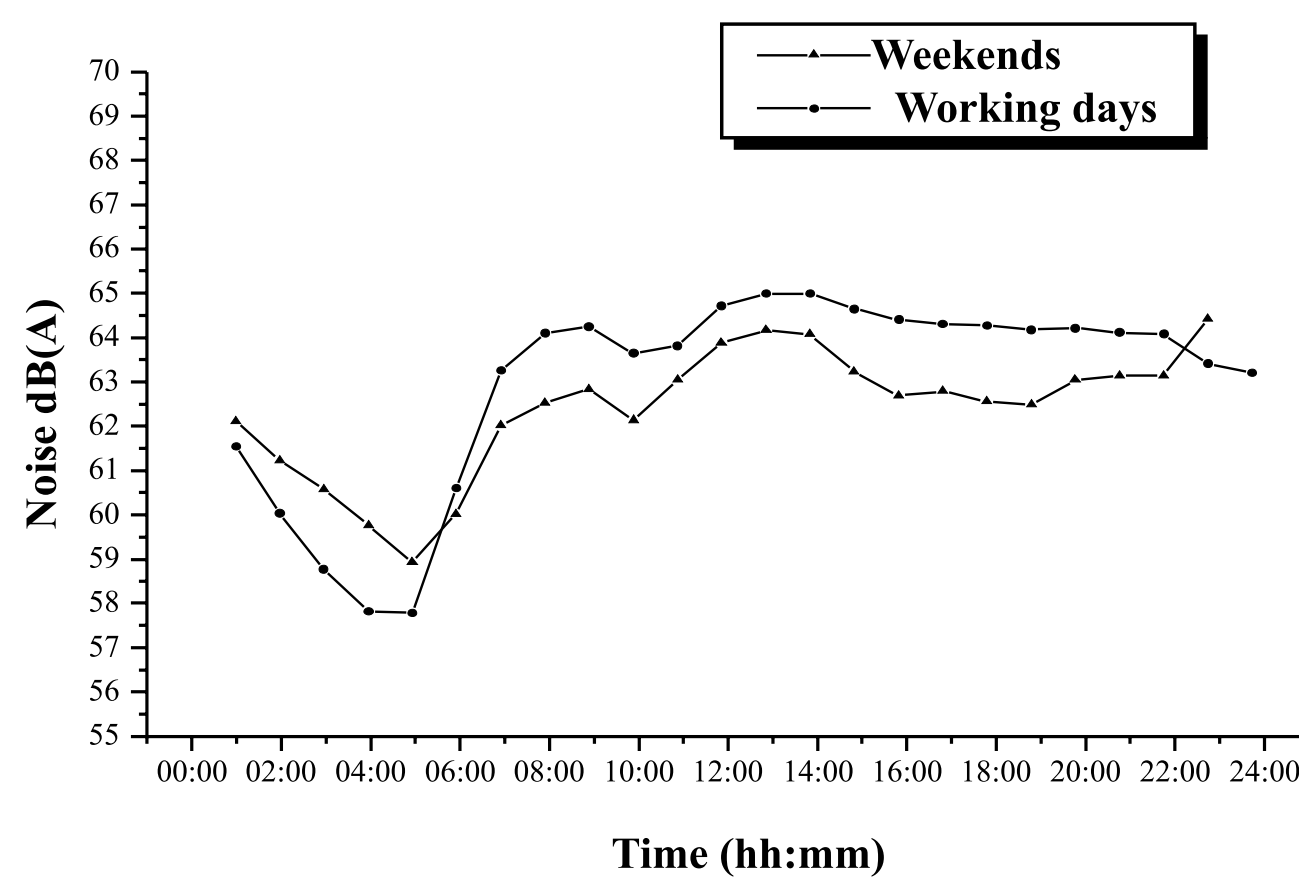

Figure 2. Diurnal variation of 1-hr and 10-min noise levels at N.Egnatia street (top) and diurnal variation of noise levels at Egnatia street during workdays and weekends, as estimated during the period 23/52/6/98 (bottom) 


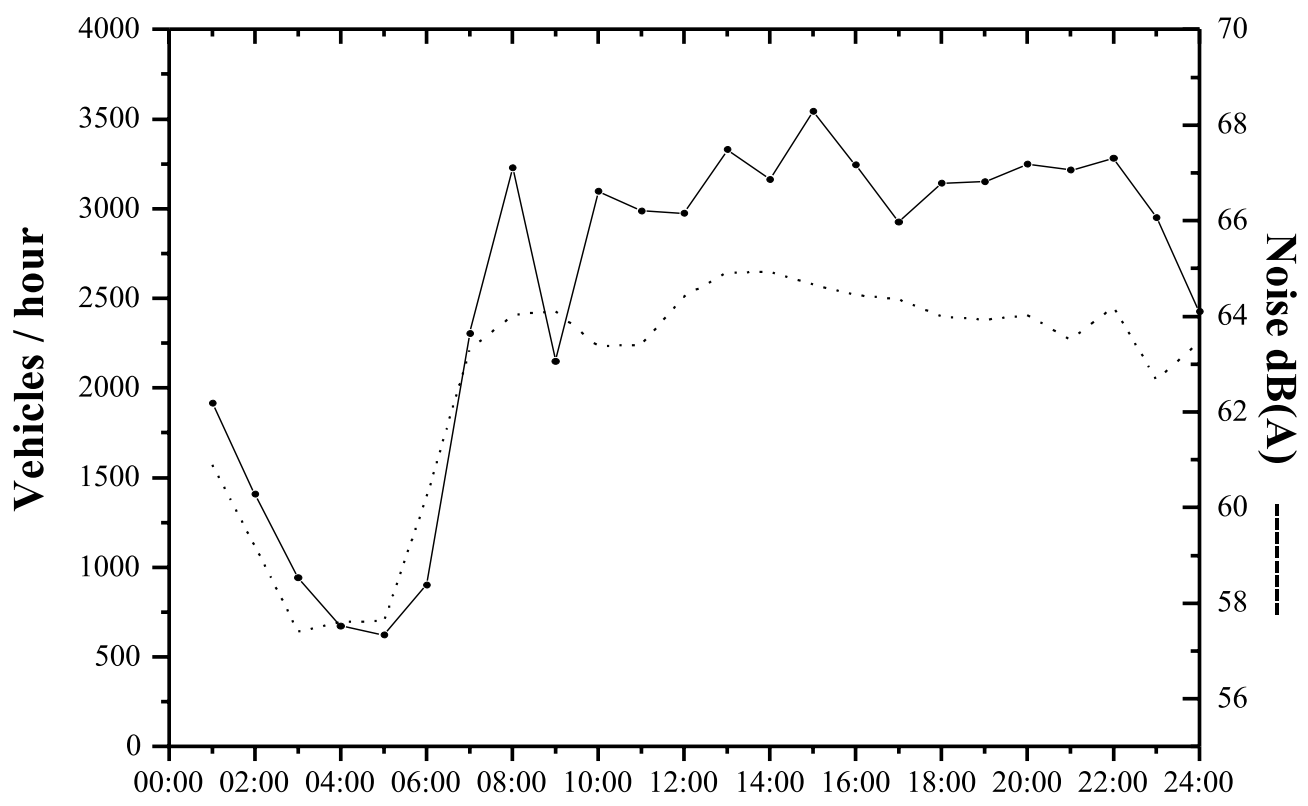

Time (hh:mm)

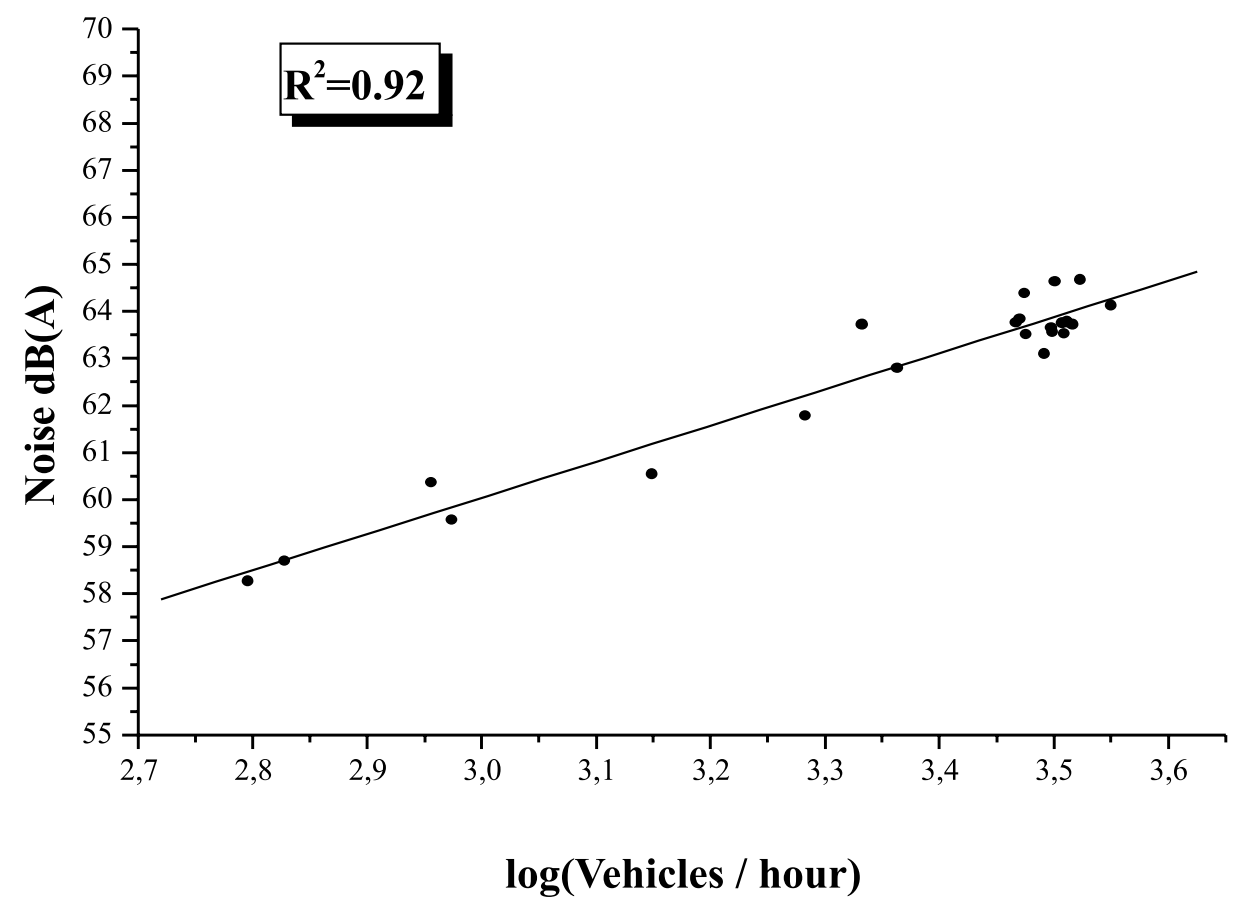

Figure 3. Mean diurnal variation of noise level and mean traffic load (top) and correlation between their hourly values (bottom) at Egnatia Str. The noise measurements were made from the $10^{\text {th }}$ to the $16^{\text {th }}$ of June, 1998, while the traffic load measurements were made during 1996 


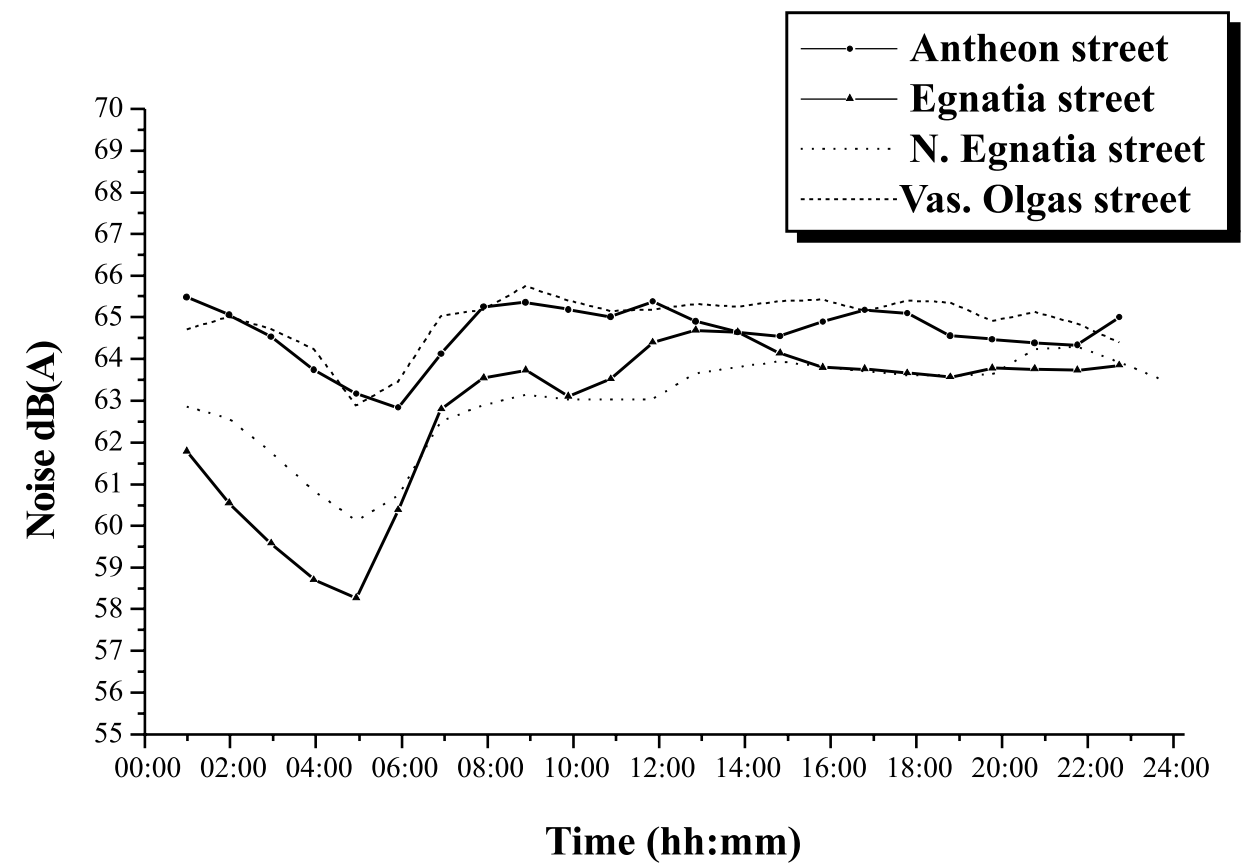

Figure 4. Comparison of hourly noise levels in four streets during one day

tive limit by 10 -min means are also observed, although these measurements were performed during a three-day holiday.

At the $2^{\text {nd }}$ floor at Vasilissis Olgas Str. the $\mathrm{L}_{\mathrm{eq}}$ varied between $\sim 64 \mathrm{~dB}(\mathrm{~A})$ and $\sim 66 \mathrm{~dB}(\mathrm{~A})$, while $\mathrm{L}_{10}$ varied between $\sim 67 \mathrm{~dB}(\mathrm{~A})$ and $\sim 69 \mathrm{~dB}(\mathrm{~A})$. The noise levels in this street are quite high, despite the fact that they were made at the $2^{\text {nd }}$ floor, at a $8 \mathrm{~m}$ height from the ground.

A comparative plot of daily noise variation at four different streets is presented in Figure 4. Measurements at Mitropoleos Str. were not used, due to the fact that they were taken only during a three-day holiday (so they are not representative of the noise levels for the street). The maximum observed mean hourly value - $66 \mathrm{~dB}(\mathrm{~A})$ - is observed in Vasilissis Olgas Str., where the noise diurnal variation is also less than that in the other streets. The minimum observed mean hourly noise value of $58 \mathrm{~dB}(\mathrm{~A})$ was observed at Egnatia Str., where noise diurnal variation was higher than that in the other streets. These differences in the amplitude of the diurnal variation can be explained by the differences in the nature of traffic in these streets, Egnatia Str. carrying mainly work-related traffic from the center of the city to the industrial area to the west, while Vasilissis Sofias Str. carrying work-related traffic from the residential areas at the east to the center of the city but also recreational traffic to the center.

In interpreting these measurements it should be kept in mind that the measurements at Vasilissis Olgas Str. were taken at the $2^{\text {nd }}$ floor, while at the other streets of Fig. 4 they were taken on the $1^{\text {st }}$ one. Given also the limited duration of the measurements, it appears that levels are of comparable order in all streets.

\section{CONCLUSIONS}

Traffic noise measurements were made at five major streets of Thessaloniki, Greece in an exploratory attempt to investigate the noise problem in highvolume traffic streets in the city. Data showed that there is a significant correlation between traffic noise and mean traffic volume. In addition, although no exceedances have been observed, the mean daily values, i.e. $\mathrm{L}_{\mathrm{eq}}(08: 00-20: 00)$, are close to the national limit of $67 \mathrm{~dB}(\mathrm{~A})$. The measurements show that Thessaloniki experiences a problem with noise levels, which, given the annual average increase in traffic volume of $6 \%$ during the past decade, might get worse. In order to better address the problem, more measurements and under a wider variety of conditions are required. 


\section{REFERENCES}

Babisch W., Ising H., Gallacher J.E.J., Elwood P.C., Sweetnam P.M., Yarnell J.W.G., Bainton D. and Baker I.A. (1990), Traffic noise, work noise and cardiovascular risk factors: The Caerphilly and Speedwell collaborative heart disease studies, Environ. Int., 16, 4025-435.

IEH, Institute for Environment and Health (1997), Workshop on non-auditory health effects of noise, Draft Report.

Morrell S., Taylor R. and Lyle D. (1997), A review of health effects of aircraft noise, Australian and New Zealand Journal of Public Health, 21, 221-236.

Nelson P. M. (1987), Transportation noise reference book, (ed.) Buttrworth \& Co., London.

NHC, Netherlands Health Council (1997), Committee on a Uniform environmental noise exposure metric, 1995: Assessing noise exposure for public health purposes, Report 1997/23E.

O'Cinneide, D. (1997), Noise Pollution, In: Environmental Engineering, Kiely G. (ed.), McGraw Hill, London, pp. 390-419.

Stathis T.C. (1981), Community noise levels in Patras, Greece, J. Acoust. Soc. Am., 98, 468-477. 